\title{
Interaction between AVR Reactive Power Control and High Power AC-DC Converter Control as possible cause of instability
}

\author{
J. L. Agüero (*), Senior Member, P. L. Arnera (*), Senior Member, R. E. Bianchi Lastra (*), Senior \\ Member, R. Molina (**), C. E. Biteznik (*), Graduate Student Member and S. Barbero (*), Graduate \\ Student Member
}

Abstract-Two oscillatory episodes took place in the Argentinean power system at 22:20 and 22:50, June $7^{\text {th }}, 2008$. The first one started when a 40 MVAr capacitors bank was disconnected and the second one started when a $500 \mathrm{kV}$ line was disconnected.

Both oscillatory episodes produced great variation of active and reactive power in several $330 \mathrm{kV}$ and $500 \mathrm{kV}$ power system nodes.

At first sight, these oscillations seemed inter-area electromechanical oscillations, but carried out studies suggest that this oscillatory behavior could be a consequence of interaction between Reactive Power Control of generators and the ac-dc Converter Control of high power loads.

Index Terms-- AC-DC Converter Control - Automatic Voltage Control - Modeling - Power System Dynamic Stability - Power System Stabilizer - Reactive Power Control - Simulation.

\section{INTRODUCTION}

A RGENTINA'S power system is composed by two parts: SIP (Sistema Interconectado Patagónico) and SADI (Sistema Argentino de Interconexión) as it is displayed in Fig. 1. The SIP is a small power system located in the south of Argentina with a peak load of $1200 \mathrm{MW}$, and the SADI is the biggest Argentinean power system with a peak load of nearly $20 \mathrm{GW}$.

Both systems are interconnected by a $360 \mathrm{~km}$ long $500 \mathrm{kV}$ line between Choele Choel and Puerto Madryn substations. A $500 / 330 \mathrm{kV}, 450$ MVA autotransformer is connected at Puerto Madryn $330 \mathrm{kV}$ substation.

Before and after SADI-SIP interconnection in 2006 several electromechanical oscillation episodes had taken place, some of them were reported [1]-[8].

The oscillatory episodes developed at 22:20 and at 22:50, June $7^{\text {th }}, 2008$, were observed in the SADI-SIP $500 \mathrm{kV}$ interconnection line and in the two lines of $330 \mathrm{kV}$ between Fuleufú and Puerto Madryn substations, see Fig. 1.

In a first approach, these oscillations were supposed to be inter-area electromechanical oscillations because the frequency of the power oscillations was near to $0.5 \mathrm{~Hz}$. This was observed in the $500 \mathrm{kV}$ SADI-SIP interconnection line.

(*) J. Agüero (jla@iitree-unlp.org.ar), P. Arnera, R. Bianchi Lastra, C. Biteznik and S. Barbero are with IITREE-LAT, Facultad de Ingeniería, Universidad Nacional de La Plata, Argentina. (**) R. Molina is with CAMMESA, Argentina.

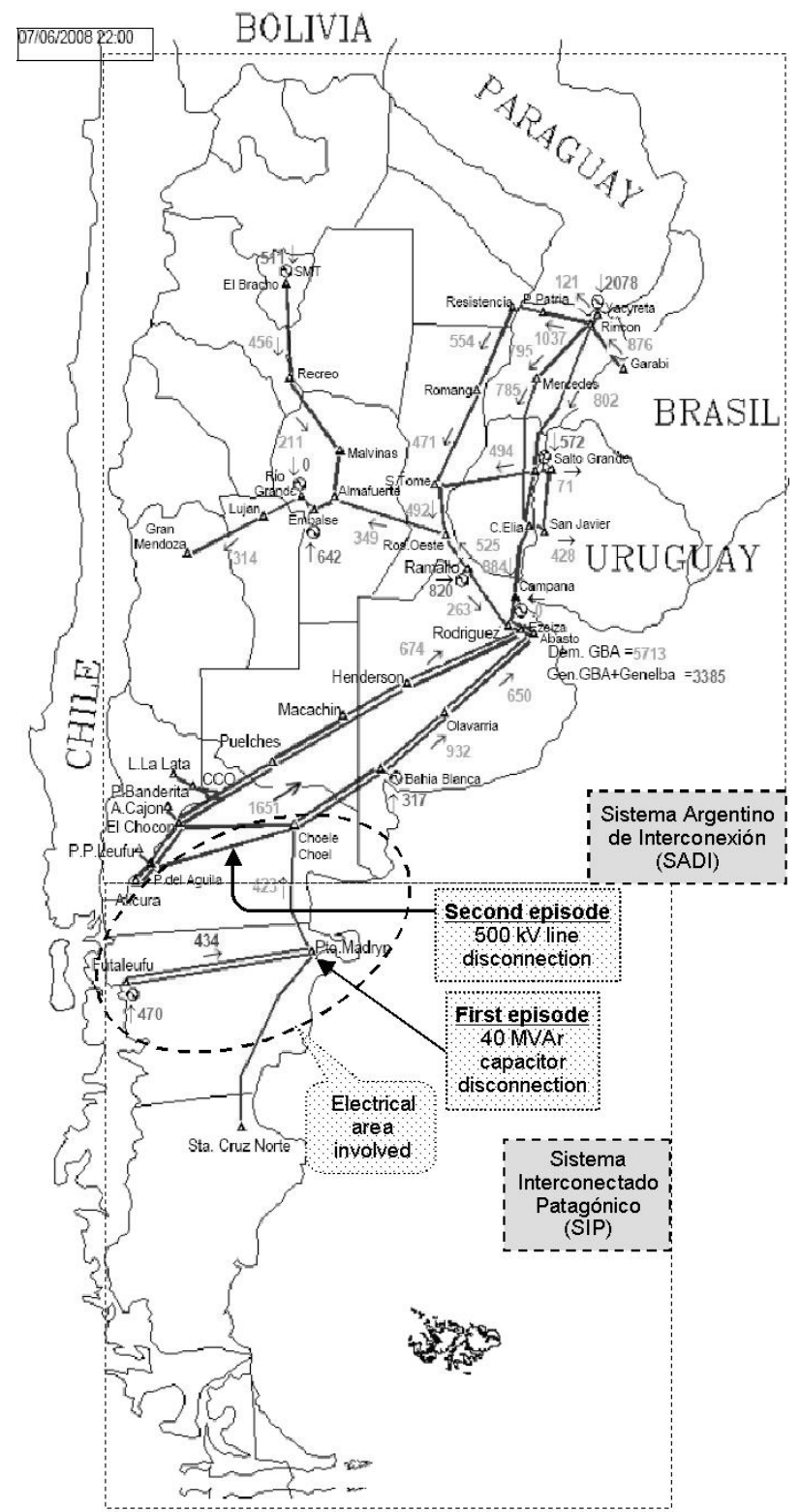

Fig. 1. $500 \mathrm{kV}$ and $330 \mathrm{kV}$ transmission systems. Pre-fault power flow: Saturday 22:20, June $7^{\text {th }}, 2008$.

However, studies carried out before and after these episodes demonstrated that the inter-area oscillation mode between SADI-SIP systems is well-damped.

To reproduce the oscillatory behavior of June 9, 2008, it was necessary to improve models of: 